\title{
Legal and ethical consequences of international biobanking from a national perspective: the German BMB-EUCoop project
}

\author{
Jürgen W Goebel ${ }^{1}$, Thomas Pickardt ${ }^{2}$, Maren Bedau ${ }^{3}$, Michael Fuchs ${ }^{4}$, Christian Lenk ${ }^{5}$, Inga Paster ${ }^{6}$, \\ Tarde M Spranger ${ }^{4}$, Ulrich Stockter ${ }^{7,10}$, Ulrike Bauer ${ }^{2}$, David N Cooper ${ }^{8}$ and Michael Krawczak ${ }^{\star, 9}$
}

The international transfer of human biomaterial and data has become a prerequisite for collaborative biomedical research to be successful. However, although a national legal framework for 'biobanking' has already been formulated in many countries, little is known about how an international exchange of data and samples might affect the legal position of national biobanks and their donors. The German Telematics Platform and the Competence Network 'Congenital Heart Defects' jointly instigated a project (BMB-EUCoop) to (i) identify and assess the legal risks ensuing for biobanks and their donors in the context of Europewide research collaborations, (ii) devise practical recommendations to minimize or avoid these risks, and (iii) provide generic informational text, contracts and agreements to facilitate their practical implementation. Four different countries were included in the study; namely, the UK, Netherlands, Austria and Switzerland. The results of the study indicate that the degree of similarity between legal systems in different countries varies according to the respective field of jurisdiction. Although personality and property rights have long been enshrined in virtually identical pieces of law, the applicable medical professional regulations were found to be somewhat heterogeneous. Furthermore, clear-cut differences were often found to be lacking between regulations that reflect either 'soft law' or the nationally binding 'hard law' that has emerged from it. In view of the potential ambiguities, the experts uniformly concluded that the rights and interests of national (in this case, German) biobanks and their donors would be best protected by explicitly addressing any uncertainties in formal contractual agreements. European Journal of Human Genetics (2010) 18, 522-525; doi:10.1038/ejhg.2009.214; published online 2 December 2009

More and more biomedical research is currently being performed by large international networks. This is particularly true for those cases in which research agendas require the establishment of large biomaterial collections for long-term scientific use (so-called 'biobanks'), or that involve the exchange of biomaterials. In Germany, most, if not all, medical research competence networks (Kompetenznetze) funded by the Federal Ministry of Education and Research (BMBF) entertain research collaborations at a European level in which the transnational collection and exchange of biomaterial has either already started or will commence in the near future (http://www.kompetenznetzemedizin.de). Furthermore, as part of the European Strategy Forum on Research Infrastructure, the European Commission is currently funding the preparatory phase of BBMRI (Biobanking and Biomolecular Resources Research Infrastructure), a strategic programme that aims to bring about the 'facilitation of [a] transnational combination and exchange of biological materials and data' (http://www.bbmri.eu). ${ }^{1}$ These developments raise the question under which circumstances the international transfer of biomaterial would be legitimate, and which legal and ethical particulars ought to be taken into account in order to protect the interests of the transferring (in the present case, German) biobank and its donors once biomaterial has left the sphere of influence of the national jurisdiction. Although large-scale probe and data transfer across Europe may well have occurred almost on a daily basis in the past, most such transfers will have involved scientists who lacked a thorough understanding of the potential legal implications of their academic pursuits, not least because the necessary expertise or the resources to procure such expertise have usually been lacking. This implies that tacit agreements between collaborating scientific institutions in different countries are not necessarily either unassailable or legally binding.

At the national level, a number of systematic studies have been performed to explore the legal and ethical framework of biobanks in different countries. ${ }^{2-11}$ Examples from Germany include the statement of the National Ethics Council on 'Biobanks for Research' released in March 2004, as well as the in-depth analysis undertaken by the Telematics Platform for Medical Research Networks (Telematikplattform für die vernetzte Medizinische Forschung, TMF) in 2006 (http://www.ethikrat.org/themen/pdf/Stellungnahme_Biobanken.pdf). ${ }^{12}$ Despite many helpful insights into the subtly different national situations obtained through these efforts, some specific aspects of international biobank collaborations have still not been addressed in sufficient detail. It must be pointed out, however, that a

\footnotetext{
${ }^{1}$ RAe Goebel \& Scheller, Bad Homburg, Germany; ${ }^{2}$ Kompetenznetz Angeborene Herzfehler, Deutsches Herzzentrum, Berlin, Germany; ${ }^{3}$ Hogan \& Hartson Raue LLP, Berlin, Germany; ${ }^{4}$ Institut für Wissenschaft und Ethik, Rheinische Friedrich-Wilhelms-Universität, Bonn, Germany; ${ }^{5}$ Abteilung Ethik und Geschichte der Medizin, Georg-AugustUniversität, Göttingen, Germany; ${ }^{6}$ RAe Ignor, Bärlein \& Partner GbR, Berlin, Germany; ${ }^{7}$ Unabhängiges Landeszentrum für Datenschutz Schleswig-Holstein, Kiel, Germany; 8Institute of Medical Genetics, School of Medicine, Cardiff University, Cardiff, UK; ${ }^{9}$ Institut für Medizinische Informatik und Statistik, Christian-Albrechts-Universität, Kiel, Germany ${ }^{*}$ Correspondence: Professor Dr M Krawczak, Institut für Medizinische Informatik und Statistik, Christian-Albrechts-Universität, Brunswiker Straße 10, Kiel 24105, Germany. E-mail: krawczak@medinfo.uni-kiel.de

${ }^{10}$ Current address: Bundesministerium für Familie, Senioren, Frauen und Jugend, Berlin, Germany.
} 
comprehensive comparative analysis of the national legal settings, even within the EU, would be a very demanding task that would require a long-term concerted effort as, for example, is already evident from the envisaged construction phase of BBMRI. This notwithstanding, one way to address the immediate needs of national biobanks for guidance in the context of international collaborations would be to undertake unilateral analyses, deliberately taking the viewpoint of the local biobank.

The German Medical Research Competence Network 'Congenital Heart Defects' (Angeborene Herzfehler, AHF) (http://www. kompetenznetz-ahf.de), which was instigated by the BMBF in 2003, is one member of the integrated 'HEARTREPAIR' project funded by the EU under FP6 as part of its 'Life Sciences, Genomics and Biotechnology for Health' section (LSH-2004-2.1.1-2, Heart repair and cardiac plasticity). The overarching goal of HEARTREPAIR, which involves 27 partners from the UK, Netherlands, Switzerland, Austria, Sweden, France, Spain and Italy, is the development of new treatments for cardiac insufficiency using either stem cells or undamaged myocardial cells from the compromised heart (http:// www.heartrepair.eu). The register of HEARTREPAIR is run by the AHF to recruit patients with congenital heart defects and to collect clinical data and DNA samples from them. All data and biomaterial will be made available to the collaborative partners in HEARTREPAIR in de-identified (anonymized) form. The patients and scientists involved currently act under the assumption that their collaboration is predicated not only upon valid informed consent by all donors but also upon legally binding agreements between the respective research institutions. However, to what extent these expectations are justified and can be realized has, in practice, not always been entirely clear. For this reason, the AHF initiated a large-scale project (BMB-EUCoop), funded by the TMF, to assess the legal framework and consequences of a Europe-wide transfer of biomaterials and data from Germany. Four different countries were included in the study; namely, the UK, Netherlands, Austria and Switzerland (ie, the major partner states in HEARTREPAIR). Although of somewhat limited scope, the results are nevertheless expected to serve as a model for comparable international cooperative ventures. In the following, we briefly summarize the main objectives and results of BMB-EUCoop.

\section{THE BMB-EUCOOP PROJECT}

Goals

The TMF-funded project 'Legal basis of EU-wide collaborations between biomaterial banks (BMB-EUCoop)' has been focused upon addressing the following three major questions:

(1) To what extent do foreign laws affect the property rights, personal rights and the right of informational self-determination of German biobank donors?

(2) To what extent does the transfer of biomaterials and data to foreign partners affect the property rights and the rights of commercial exploitation of German biobanks?

(3) How can the positions of German biobanks and their donors be protected against the risks identified under 1 and 2, and how can such protection be enforced in practice, if so required?

It should be emphasized that these questions cannot be addressed simply by reference to international private law, that is, the array of international conventions that regulate the handling of lawsuits in which different judgements would ensue, depending upon which national jurisdiction was applied as the lex causae. Not only does the national implementation of international private law vary between different countries, but most national regulations leave considerable room for interpretation. Furthermore, in the context of international biomaterial transfer, it is important to note that, according to German law for example, legal issues regarding inanimate matter (including biomaterials) are subject to the jurisdiction of the country in which the inanimate matter is physically located. Therefore, a comparison of the personal and property rights framework of biomaterial transfers in selected countries appears to be warranted.

In the pilot phase of BMB-EUCoop, a survey was carried out among German biobanks to assess the need to address the above questions. The project proposal was circulated among several biobank executives and received widespread approval, in particular from the BMBF-funded network alliance on rare diseases (http://www.bmbf.de/ de/1109.php). Clarification of the legal framework of international biomaterial and data transfer is of specific importance for these diseases owing to the relatively small number of patients typically available for study in the individual participating countries. Although the primary purpose of BMB-EUCoop was intended to be the provision of legal and ethical guidance to German biobanks, it was also expected to confer greater international visibility and recognition upon key national biobanking efforts.

\section{Methods}

The following tasks were completed in BMB-EUCoop:

(1) Specific expert reports were solicited on the potential legal conflicts arising from an international biomaterial and data transfer, from the standpoint of a German biobank, and focusing upon collaborations with institutions in the UK, Netherlands, Switzerland and Austria.

(2) On the basis of these reports, short summaries of the potential legal and ethical risks to German biobanks were produced.

(3) Upon the foundations laid by (1) and (2) above, the experts drew up generic contracts, standard operational procedures and other documents that ensured legal validity on the part of the German biobank.

(4) Finally, proposals were put forward as to how potential legal and/or ethical controversies between a German biobank and its international partners might be resolved by means of alternative dispute resolution (ADR).

The BMB-EUCoop project was initiated in December 2006 through an expert workshop, organized by the AHF, at which potential authors were identified for the expert reports and where the contents of these reports were agreed upon in broad outline. The reports and generic texts were then finalized in Autumn 2008 and were at the final revision stage during the preparation of this article. Although summaries of the reports, in German and English, are already available for downloading from the TMF website (http://www.tmf-ev.de/BMBEUCoop), the fulllength German texts will be published (in book format) only in late 2009. Bibliographic details (such as title, authors and publisher) and the conditions of purchase will be announced in due course on the TMF website (http://www.tmf-ev.de/BMBEUCoop).

In particular, the expert reports focused upon the following areas of potential conflict:

(1) human and personal rights

(2) property rights

(3) medical professional regulations

(4) commercialization and intellectual property rights

(5) supranational and international rights 
(6) benefit sharing

(7) criminal law and prosecution

(8) data and privacy protection

(9) mechanisms of ADR.

\section{Results}

In the following, we summarize the main results of the BMB-EUCoop expert reports.

(1) A similar requirement for the protection of donors' personality rights was identified in all five legal systems studied (ie, in Germany and in the four other European countries). The expert reports contain a number of practical recommendations that relate to how these rights might be balanced against the research interests involved, when, for example, it comes to enforcing compliance with a donor's original consent. A consensus view was reached that the position of the German donors would be best protected by introducing these recommendations into contractual agreements between the German biobank and its foreign partner(s), including mandatory proof of compliance if this were feasible.

(2) In terms of property rights, the legal situation in the five European countries was also found to be nearly identical. Thus, whereas the donor of a given biomaterial sample is usually also the owner of that sample, donors are free to transfer their property rights to another party if they so desire. However, minor differences were found to exist regarding, for example, the requirement for an explicit (ie, written) transfer of these rights from the donor to the biobank if the latter were to wish to acquire them. Again, the consequences of any divergent regulations could be remedied by appropriate stipulations in contractual agreements. It must be kept in mind, however, that the donor's personal rights would generally supersede the existing property rights in all five countries under study, irrespective of who actually owned the biomaterial in question.

(3) Compared with the personal and property rights framework, the medical professional regulations applicable to the transfer abroad of biomaterial and data from Germany are more heterogeneous. Considerable differences were found to exist, for example, in terms of storage and documentation duties, or the requirement to inform donors of relevant research results. On the other hand, the statutory requirement of physician confidentiality applies to research on human biomaterial in all the countries under study. Furthermore, several national guidelines, albeit non-legally binding, recommend the involvement of an ethics committee prior to any such research programme receiving formal approval. Again, the experts recommended that any possible discrepancies could and should be avoided by contractual provisions.

(4) In contrast to the situation with human organs, there appear to be no fundamental ethical reservations in the five countries under study regarding the commercialization of biomaterials in general. However, this discussion is not yet complete and for certain types of biomaterial, including, for example, human gametes and embryonic stem cells, certain legal restrictions exist that cannot be contractually disregarded. Furthermore, Article 21 of the Council of Europe's 1997 Bioethics Convention clearly requires that 'the human body and its parts shall not, as such, give rise to financial gain' (http://conventions.coe.int/ treaty/EN/Treaties/Html/164.htm). Whether this also relates to biomaterials that have been obtained exclusively for research purposes will be a matter for discussion and may well receive different levels of approval in different countries.

(5) Patenting of biomaterials and of entities derived thereof is regulated in all five countries under the EU Biopatenting Directive (Directive 98/44/EC) (http://eur-lex.europa.eu). Furthermore, in general, database resources benefit from sui generis protection under the EU Database Protection Directive (Directive 96/9/EC). However, as national differences still exist in terms of the actual implementation of these directives, patenting and intellectual property rights issues relevant to a given collaboration should also be regulated by contractual agreement.

(6) For the international and supranational legal regulations of interest, there are often no clear-cut differences between normative and ethical regulations, guidelines or documents that reflect either 'soft law' (defined as quasi-legal instruments that do not have any legally binding force) or the nationally binding (ie, legally enforceable) 'hard law' that invariably emerges from it. In practice, implementations of soft law regulations into the national jurisdiction still appear to be in their infancy in Europe. This uncertainty further highlights the need for explicit contractual agreements to protect the position and interests of internationally operating biobanks and their donors.

(7) The same applies to the issue of benefit sharing, that is, the involvement of donors in the pecuniary and/or non-pecuniary outcomes of research on their biomaterials. Although most regulations in this field are part of the soft law, and are therefore not yet legally binding in the countries under study, they may nevertheless put researchers under morally binding ethical obligations.

(8) Matters regulated by criminal law include neglect of duty, negligent injury, privacy violation and the possibility of confiscation. Here, the legal frameworks in the five countries examined were found to be fairly similar. Where there were national differences, as, for example, in the case of a state's entitlement to biomaterial confiscation, these cannot simply be alleviated by contractual agreements because neither criminal law nor the means of criminal prosecution are part of the dispositive law in modern societies. Whether donors should be informed explicitly of this fact is the topic of ongoing discussion.

(9) Regarding data and privacy protection, an exchange of biomaterial and data between the countries under study would not appear to pose any risks that do not already exist at the national level. The national jurisdiction in this context is relatively homogenous, not least because of the EU Data Protection Directive (Directive 95/46/EC). However, inconsistencies were found to exist in legal practice, for example, with regard to the applicability of the national data protection policy to the biomaterial itself. Furthermore, different levels of administrative stringency and efficiency in one country could jeopardize national regulatory standards in another. In this case, German biobanks were advised in general to place the foreign partner under an obligation to guarantee the maintenance of the German standard, which is in any case tantamount to a compliance with the EU Data Protection Directive, as a precondition for the donors' long-term confidence and trust in the biobank. It should be mentioned in this context that the German Data Protection Act (Bundesdatenschutzgesetz) restricts data transfer to those foreign countries of which the standards of data protection are comparable to those pertaining in Germany (http://www.gesetze-im-internet.de/bdsg_1990/). This is currently assumed to be automatically the case only for the EU and a few other countries, including Switzerland. 
(10) As, in practice, the regulations governing how to deal with legal conflicts differ quite widely between the countries studied, for example, in terms of the jurisdictional responsibility in a given case, the experts came to the conclusion that mechanisms of ADR would usually be preferable to taking a dispute to court. In this way, most conflicts over the use of biomaterial and data could be resolved more quickly, more cheaply and with greater scientific expertise on hand.

On the basis of the expert reports, generic texts were produced in the second part of BMB-EUCoop that should not only help to avoid the identified legal risks but should in practice also allow any regulatory gaps to be bridged. These texts were not intended to prompt 'battles of contracts', but rather to serve as a means to avoid extensive and unfruitful legal disputes. In the preparation of the texts, the standpoint taken was again that of enforcing the positions and interests of the German biobank and its donors. The following generic texts were produced:

(1) a widely usable piece of text to inform potential donors about the envisaged transfer of their property rights to the biobank and about the intended use(s) of their biomaterial;

(2) a consent form referring to the above information;

(3) a contract of collaboration between a German biobank and a foreign institution;

(4) a material transfer agreement for repeated use in long-term collaborations;

(5) a contract for the processing of German biomaterial by a foreign institution;

(6) a guide to arbitration for use in potential situations involving a legal and/or ethical conflict between a German biobank and a foreign institution.

These generic texts are available for downloading in German and English from the TMF website (http://www.tmf-ev.de/BMBEUCoop). They are phrased in such a way that they can be adapted to the individual situation with minimum additional effort. It has been recommended by the authors, however, that any modified generic text be approved by a specialist advisor in contractual law before being put to practical use.

\section{OUTLOOK}

The detailed expert reports produced in BMB-EUCoop revealed that countries potentially involved in international biobank collaborations can have substantially different legal and ethical frameworks with respect to the handling and use of human biomaterial in scientific research. This is the case even for those countries, considered in BMB-EUCoop, that are members of the European Union (and hence for which at least parts of the legal systems have been convergent). Differences exist with respect to German law, which implies that, on a mere legal basis, the rights and ethical positions of German biobanks and their donors are not necessarily guaranteed in international collaborations. The best way to clarify this situation is to make detailed contractual agreements covering the intended obligations and entitlements of both parties.

It may be argued in this context that entering into contractual agreements always operates on the principle of 'it takes two to tango'. It may thus be unclear whether foreign scientific institutions would be either prepared or entitled to accept the conditions set by national biobanks, particularly with regard to intellectual property rights and commercialization. However, the particularly sensitive character of biomaterials and their associated data invariably create an imbalance between the legal positions of the two parties. While the donors' consent puts biobanks under an obligation of compliance that supposedly extends to third parties, collaborating institutions always have the choice to opt out of such collaborations, if the conditions are deemed to be unacceptable. Furthermore, article 3 of the Convention on the Law Applicable to Contractual Obligations (Rome I Convention) (http://eur-lex.europa.eu) gives the parties to a contract freedom of choice over the applicable law. This implies that both the nature and content of mutual agreements between biobanks and their international partners are largely at their own discretion.

Clearly, clarification by way of contracts is possible only for those legal issues that are part of the dispositive law and hence that are amenable to contractual regulation in the first place. For many legal positions pertaining to personal rights, data protection law or criminal law, this is either not possible or instead subject to serious restrictions. It would of course greatly facilitate international scientific collaborations if the existing discrepancies were to be resolved by changes in national and/ or international law. However, until such a time as such discrepancies are resolved, German biobanks (and perhaps others) are advised to use the generic texts produced in BMB-EUCoop to avoid conflicts and unwanted loss of rights, bearing in mind, however, that both the validity and utility of these texts have still to be proven in practice. It would also be interesting to see similar projects performed in other countries, this time adopting the standpoint of local biobanks. Such projects will become essential if we are to facilitate a comprehensive international network of biobanks as envisaged, for example, by BBMRI. In the absence of a formal assessment of the legal basis and practical consequences of such an endeavour, any attempt to create and promote a platform for international biomaterial and data exchange would have to operate in a judicial and ethical grey zone, and hence could run a serious risk of eventual failure.

\section{CONFLICT OF INTEREST}

The authors declare no conflict of interest.

\section{ACKNOWLEDGEMENTS}

We thank Johannes Drepper (TMF, Berlin) for his excellent administrative support, the members of the TMF Working Group 'Biobanks' for monitoring the project, and Tim Lu (Kiel) for helpful comments on the manuscript. This work was supported by the German Federal Ministry of Education and Research through TMF project grant V010-02 BMB EU-Coop.

1 Yuille M, van Ommen GJ, Brechot C et al: Biobanking for Europe. Brief Bioinform 2008; 9: 14-24.

2 Winickoff DE: Biosamples, genomics, and human rights: context and content of Iceland's Biobanks Act. J Biolaw Bus 2001; 4: 11-17.

3 Anderlik M: Commercial biobanks and genetic research: ethical and legal issues. Am J Pharmacogenomics 2003; 3: 203-215.

4 Caulfield T: Tissue banking, patient rights, and confidentiality: tensions in law and policy. Med Law 2004; 23: 39-49.

5 Richardson G: The banking of embryonic stem cells: the legal and ethical framework in the UK. Law Hum Genome Rev 2004; 20: 147-160.

6 Gibbons SM, Helgason HH, Kaye J, Nõmper A, Wendel L: Lessons from European population genetic databases: comparing the law in Estonia, Iceland, Sweden and the United Kingdom. Eur J Health Law 2005; 12: 103-133.

7 Clark G, Lipworth W, Les B, Little JM, Kerridge IH: An empirical study of tissue banking in Australia: navigating regulatory and ethical challenges. J Law Med 2006; 14: 102-109

8 Artizzu F: The informed consent aftermath of the genetic revolution. An Italian example of implementation. Med Health Care Philos 2008; 11: 181-190.

9 Haga SB, Beskow LM: Ethical, legal, and social implications of biobanks for genetics research. Adv Genet 2008; 60: 505-544.

10 Nys H, Fobelets G: The regulation of biobanks in Spain. Law Hum Genome Rev 2008; 29: 169-188.

11 Zika E, Schulte In den Bäumen T, Kaye J, Brand A, Ibarreta D: Sample, data use and protection in biobanking in Europe: legal issues. Pharmacogenomics 2008; 9: 773-781.

12 Simon J, Paslack R, Robienski J, Cooper DN, Goebel JW, Krawczak M: A legal framework for biobanking: the German experience. Eur J Hum Genet 2007; 15: 528-532. 